Dr Thomas D. Lacki

is senior director of knowledge management globally for Carlson Marketing Group, a leading relationship marketing agency. Tom has a PhD in cognitive psychology, research methodology and statistics and over 15 years of marketing experience.
Keywords: alignment, best practices, CRM, measurement, relationship marketing, strategy
Thomas D. Lacki,

Carlson Marketing Group 1405 Xenium Lane North Plymouth

MN 55441-8296, USA

Tel: +17632121548

Fax: +1 7632126168

E-mail: tlacki@carlson.com

\section{Achieving the promise of CRM}

\author{
Thomas D. Lacki \\ Received: 27 January 2003
}

\begin{abstract}
Enduring profitable relationships are what all businesses seek, but guidance on how to achieve them has been largely prescriptive and based upon theory. What the discipline of customer relationship management (CRM) has lacked is a descriptive investigation of those principles and practices that drive excellence. In partnership with the American Productivity and Quality Center, a world-renowned independent leader in benchmarking, both quantitative and qualitative data from 32 companies across North America were gathered and analysed in order to ameliorate this shortcoming. The ten qualitative findings collectively reveal what it takes to establish and foster profitable relationships with customers and other stakeholders, such as channel partners and employees. Relying primarily upon these research insights, the paper documents how leading organisations achieve superior business results through CRM and describes the key elements of a winning strategy, the effective ways in which organisations align their resources and relationships and the mechanisms by which measurement and accountability are realised. In brief, the paper focuses upon answering this single question: what are the best practices actually in use today among exemplary relationship-focused organisations that are proven to deliver business results?
\end{abstract}

\section{Introduction}

Intuitively every senior executive recognises the importance of relationships in achieving business success. Relationships with your customers, with your distribution channel, with your suppliers and with your employees are all known to be key. Relationships that are founded upon shared knowledge and trust, are resilient to short-term opportunistic gain and are persistent: these are the outcomes businesses seek. They resonate with our own experience, both personally and professionally, and motivate many companies to spend an average of US\$75 $\mathrm{m}^{1}$ on establishing customer contact centres, purchasing technology applications, building data warehouses and engaging in data mining. Despite the investment of conviction and of cash, victory in achieving authentic and productive relationships remains elusive for many — but not impossible for all.

Successes do, of course, exist and are well publicised. ${ }^{2}$ However, the stories of widespread failure are worrisome, and appear to be growing in number. A majority of companies are now unable to cost-justify their customer relationship management (CRM) investment, ${ }^{3}$ and over half of all CRM projects fail to meet their objectives. ${ }^{4}$ Even more troublesome 


\section{From general success factors...}

\section{... to specific practices}

\section{Agenda}

are reports documenting that a poorly implemented solution does not simply fail to improve customer satisfaction and loyalty, but in fact has an adverse effect on these measures. ${ }^{5}$ Failure does more than waste a company's resources; it negatively impacts the business by damaging long-standing customer relationships. ${ }^{6}$

What is it that characterises the most successful relationship-focused organisations? How do they build better relationships with their key constituencies? Condensing all that has already been written, it can be said with certainty that outstanding organisations excel in three realms: in thinking, in doing and in measuring. They know the importance of getting the strategy right, of making the organisational and process changes required to support that strategy and of achieving accountability by documenting a return on the investment. A focus on anything less than all three is a good predictor of failure.

A recognition of these three dimensions of success is valuable, but more so would be the identification of specific practices that underlie successful CRM strategies, of the ways in which organisations align their resources and their relationships and of how they measure themselves. As a discipline CRM has suffered because of its wealth of generalities and its paucity of actionable insights. With the objective of ameliorating that shortcoming, research ${ }^{7}$ was conducted in partnership with the American Productivity and Quality Center, a member-based non-profit serving more than 500 organisations around the world in all sectors of business. The investigation examined behaviour patterns in 32 organisations across North America to begin to address the question: what are the best practices actually in use today among exemplary relationship-focused organisations that are proven to deliver business results? It is a fool's errand to seek to find rigid formulae that will guarantee success. However, it is equally a fool's folly not to begin by first understanding, adapting and applying the successes of others.

The research discovered ten central findings in the areas of strategy, alignment and measurement that collectively serve to document the principles, practices and processes that enhance the likelihood of CRM success. In the following pages, each lesson will be described, its application illustrated and a touchstone provided so that the reader may gauge her or his own company's progress toward achievement of these best practices.

\section{Method}

The set of participants included organisations from the USA ( 81 per cent) and Canada (19 per cent), and represented numerous and diverse industries. Thirty-seven per cent are business-to-business marketers, 16 per cent business-to-consumer, and the remaining 47 per cent consider themselves to be both.

Among these organisations, four were identified as exhibiting exemplary relationship practices and examined in detail. The best practice organisations were chosen based upon a process involving secondary literature reviews, nominations from an independent subject matter expert $^{8}$ and completion of an in-depth screening questionnaire designed 


\section{Best practice organisations}

\section{Key questions}

to probe their CRM activities. Each organisation faced a variety of problems or opportunities, thereby increasing the breadth of the information gathered for the research; each had a CRM strategy that could be clearly expressed and understood, to facilitate learning and knowledge transfer; and each demonstrated measurable results as a consequence of their CRM activities. The organisations so distinguished were the following:

- Canadian Imperial Bank of Commerce, one of the leading financial institutions in North America with more than 8 million retail and 8,000 corporate banking customers

- Harrah's Entertainment, a consumer marketing company that owns and operates 24 casinos across the USA

- Roche Pharmaceuticals, a division of the Roche Group, an international healthcare company active in more than 100 countries, for their CRM programme (XENICare ${ }^{\circledR}$ ) designed to enhance the effectiveness of a prescription weight-loss medication (Xenical ${ }^{\circledR}$ )

- Sears Canada, the largest single retailer of general merchandise in Canada.

During the third and fourth quarters of 2001 quantitative and qualitative data were gathered through anonymous questionnaires. In addition, the best practice organisations were visited on-site to permit the face-to-face collection of additional in-depth qualitative information using a semi-structured approach involving the presentation and discussion of predetermined key topics.

\section{Research objectives}

The objectives were to address the following three questions.

- What are the key elements of a winning CRM strategy? For this question, the task was to seek to understand the general considerations, approaches and principles underlying successful strategies that could be broadly applicable.

- How do best practice organisations align their economic and organisational resources and relationships to drive success? Answering this question involved an investigation of how best practice organisations achieve results by acting upon their CRM strategy.

- How do exemplary relationship-focused organisations measure themselves? The mission here was to explore the collection and utilisation of quantitative data by best practice organisations to drive and demonstrate both value and marketing accountability.

In summary, the goal of this research study was to 'paint' a broad 'landscape' of exemplary CRM practices in the areas of strategy, alignment and measurement. A total of ten findings were identified, four each in the strategy and alignment areas together with two pertinent to measurement. 


\section{An encompassing view of CRM}

\section{Three relationship dimensions}

\section{Findings: Strategy \\ Best practice organisations develop a clear, holistic vision of all stakeholder relationships}

The first insight is the most encompassing and addresses the set of constituencies included within a successful CRM strategy: it is holistic and integrated across numerous audiences. Best practice organisations think about all of their key stakeholders in developing their CRM strategy, including but not limited to their customers.

Those stakeholders most often included within a CRM strategy belong to one of three clusters. First are those most tightly aligned with a company's revenue stream: customers, individuals to whom goods and services are directly sold, and channel partners, those through whom sales occur. Not surprisingly, these are the constituencies ranked among the most important.

The second cluster has a corporate focus, including employees, management, the board of directors and the shareholders. Interestingly, best practice organisations recognise that the success of a CRM strategy depends not only on those constituencies from whom revenue is collected (customers and channel partners), but also upon those from whom resources are allocated (eg management).

The third cluster highlights those who supply products or services to the organisation, or otherwise control its activities: vendors or suppliers, and regulatory agencies or labour unions. Best practice companies know that it is important to build better relationships with these constituencies, too.

Harrah's Entertainment, for example, speaks to its management, to its board of directors and to its shareholders about the importance of CRM by making it the focus of its annual report, while Sears Canada places customers at the centre of its CRM strategy, but also emphasises sales and service (eg employees) and merchandising (eg suppliers). Finally, Roche Pharmaceuticals includes physicians (ie a 'regulatory' constituency) in its CRM strategy, since their weight-loss medication can only be purchased with a prescription.

A representation of the bi-directional interactions or linkages among constituencies is provided through the Carlson Relationship Marketing Map, a framework for helping companies document, understand and diagnose $^{9}$ the comprehensive set of relationships to be addressed in a successful CRM strategy (see Figure 1). The constituencies are denoted by spheres and arrows are used to represent a directional behaviour or expectation within the key relationship dimensions of brand, sales and service, and culture. For example, the cultural dimension captures the relationships between a company and its employees, involving behaviours that the company seeks from its employees (eg productivity) and the expectations that the employees have of the company (eg honesty and frequent communication). Using this framework, consider in more detail the case of Roche Pharmaceuticals.

\section{Brand}

Relationships between Roche Pharmaceuticals as an organisation and the pharmacies, physicians and customers (patients) capture the brand 


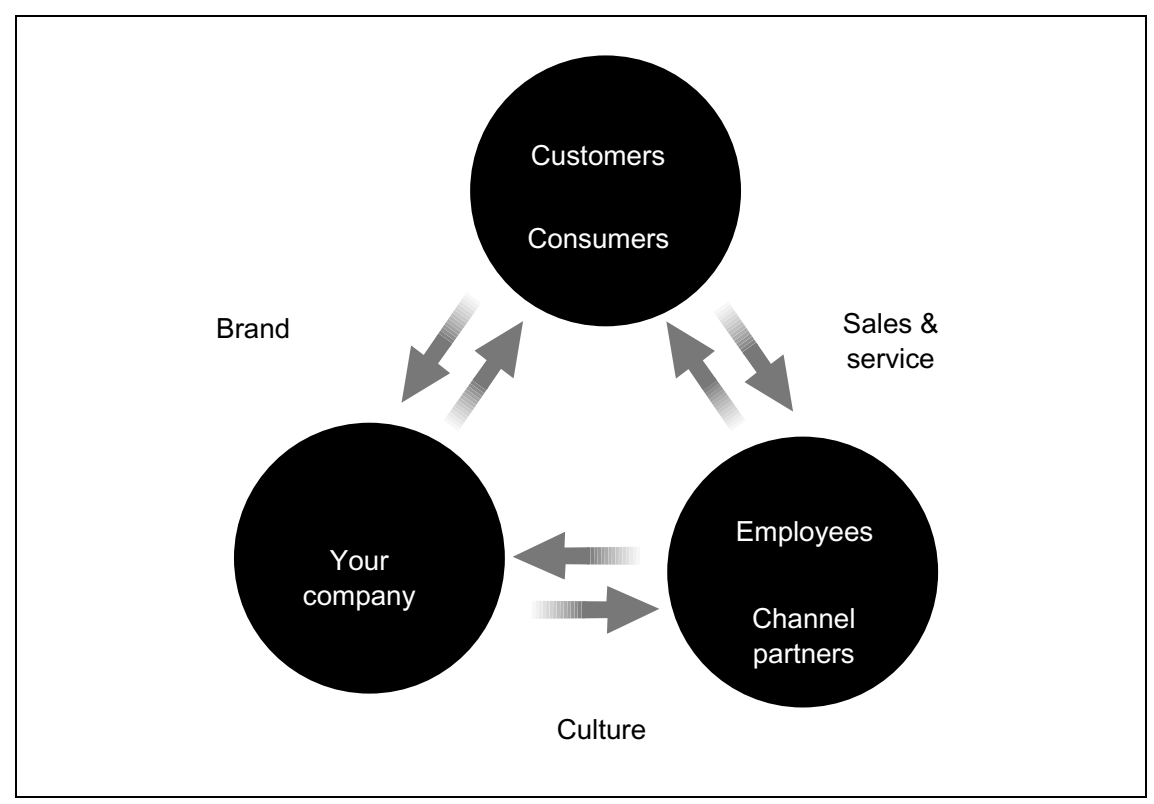

Figure 1: The Carlson Relationship Marketing Map ${ }^{\mathcal{C}}$

promise: an effective and safe pharmaceutical solution for weight loss. In return for their marketing efforts, Roche Pharmaceuticals expects the pharmacies to stock Xenical ${ }^{\circledR}$, physicians to be knowledgeable about the drug and prescribe it and customers to request it by name.

\section{Sales and service}

The relationships between Roche Pharmaceuticals' employees and customers represent service expectations (eg receiving knowledgeable consulting from registered nurses and dieticians and assistance in handling insurance claims). On the reciprocal side of this relationship, Roche Pharmaceuticals' employees expect the customer to complete a patient profile and to participate in scheduled follow-up telephone conversations, for example. Additional service expectations and behaviours also exist between Roche Pharmaceuticals' employees and the pharmacy and physician stakeholders (eg providing continuous nutritional information support and motivation for their patients).

\section{Culture}

The relationship Roche Pharmaceuticals has with its employees (ie XENICare ${ }^{\circledR}$ staff) is centred around corporate culture. Roche Pharmaceuticals' employees expect (and receive) training and recognition. In return, Roche Pharmaceuticals expects to have knowledgeable employees who delight customers. Through a reciprocal employer/employee relationship, trust and commitment are built. ${ }^{10}$

In order to facilitate the process of adapting and applying these insights to your own organisation, consider two questions. 


\section{Customer valuation and differentiation}

- Who are all of our key stakeholders with whom it is important to build better relationships? Has our organisation explicitly identified the set of interacting constituencies that form the web of relationships surrounding our enterprise?

- Has our organisation prioritised the set of stakeholders with whom it is important to build winning relationships, based upon an understanding of the investment required to impact on each and the expected business return?

In review, this finding highlights the inclusive nature of CRM within best practice organisations. Stated differently, it is not CRM in the sense of customer but rather constituency relationship management: considerably more broad, and considerably more challenging.

\section{Best practice organisations understand the relative importance of their customers and allocate resources accordingly}

The second finding recognises that customer heterogeneity is a precondition for relationship marketing. It is in fact the differences that are addressed through a superior CRM strategy rather than a focus upon the average. Treating customers uniquely — based not only on their worth but also upon their wants and needs - is at the heart of CRM success. To do so involves differential resource allocation.

This concept has been widely discussed among marketers; what is noteworthy here, however, is the fact that, unlike many organisations ${ }^{11}$ best practice companies act upon it. Harrah's Entertainment, for example, includes at least 80 standardised segments in every customer promotion, based upon frequency of play, amount and observed versus predicted behaviour. When one of their best customers has an especially unlucky day (defined as the difference between their actual spend and their 'daily theoretical profitability'), they might return to their hotel room in the casino and find an unexpected gift to help ameliorate the disappointment. Their CRM strategy is described by the chairman and chief executive officer in a letter to shareholders this way:

'First, let us tell you how pleased we are with the results of our operating strategy. It focuses on building enduring customer relationships by using our innovative technology, marketing expertise and financial strength to provide our guests with superior service and high-quality amenities. ${ }^{12}$

In order to facilitate the process of adapting and applying these insights to your own organisation, consider two questions.

- Do we know by name who are our best customers, our best channel partners and our employees who are most effective at building winning relationships?

- Are we able to tailor communications and services individually?

In review, this finding highlights the importance of recognising that there is a continuum of 'bonding' and value along which individuals are 
distributed; and understanding from where each relationship starts and to where each may potentially progress is key to increasing growth and profits through CRM.

\section{Best practice organisations centrally coordinate the CRM strategy and customise it locally}

Senior management within best practice organisations characterise relationship marketing as the 'very essence of the business itself'. For these exemplary organisations, some facets of that 'essence' are centralised while others are decentralised.

What do best practice organisations centralise? Primarily three elements:

\section{Centralisation}

- the overall enterprise-wide strategy, in order to ensure consistency of focus and direction

- the creation and maintenance of a unified corporate memory of key relationships (often captured within a relational database management system), in order to enable a consistent customer experience no matter where or when the customer 'touches' the company

- a knowledge management function, in order to ensure that insights gained in one part of the enterprise are disseminated quickly and effectively.

There is a balance between these centralised elements and corresponding decentralised facets:

\section{Decentralisation}

- best practice organisations encourage local customisation of the tactics, in order to match more closely unique circumstances of markets

- they gather key facts about the relationship at each contact, in order to understand deeply the pattern of customer/company interactions

- they engage in testing innovative new tactics, in order to drive continuous improvement.

How do best practice organisations actually do this? Harrah's Entertainment, on the one hand, encourages customer promotions to be customised by its local properties; and, on the other hand, has established a marketing council composed of regional personnel that meets quarterly. Through these two avenues, it achieves the desired balance between driving local innovation and sharing marketing successes among properties within the enterprise.

Sears Canada gathers data from customers across numerous local touchpoints, including retail points of sale, 'teleshopping' catalogue sales interactions through call centres and Internet purchases. All such decentralised information, however, is stored in one database in order to provide a complete picture of each customer.

To facilitate the process of adapting and applying these insights to your own organisation, consider these questions. 


\section{Thoughtful progression}

- What are all the contact points between our customers and our company? What could we capture and learn from each such contact? If we had that information today, how would it impact on our marketing activities and success?

- Is there a feedback mechanism for insights developed at the 'granular level' (whether by geographic locality, organisational unit or customer segment) to be captured and leveraged across the enterprise? What is the cost associated with not taking advantage of these continuous learning opportunities?

In review, by balancing these three dimensions from both central and distributed perspectives, best practice organisations achieve a single strategic direction, a single representation of stakeholder relationships and a single repository of 'lessons learned'.

\section{Best practice organisations deploy CRM in stages, yet possess and are guided by a comprehensive vision}

Simply stated, this finding means that it is not necessary (nor advisable) to 'boil the ocean', but gradually to expand the breadth and depth of a CRM strategy based upon a 'road map'. Focusing initially on limited pilots, specific constituencies or enabling capabilities is the way in which best practice organisations have achieved their success - all while maintaining an 'end-in-mind' vision to guide the journey.

There is a progression through which best practice organisations proceed to become customer-centric: ${ }^{13}$

- initial planning, in which clarity of intent and the business problems to be solved are articulated

- assessments to ascertain the status quo, encompassing customers, the competitive landscape and the company's own knowledge-based competencies and performance-based capabilities

- establishment of a future state, in which the question 'what might be?' is answered through visioning and consideration is given to strategic gaps in the areas of people, processes, knowledge and technology

- creation of a business case, in which authorisation and funding is secured based on the estimated expenditures and expected return

- change management and implementation, in which the 'burning platform ${ }^{14}$ is communicated and addressed through action.

To become customer-centric involves a journey from strategy, through execution, to results. It encompasses building a case for change, creating a CRM 'roadmap', establishing strategic clarity, defining a CRM architecture or blueprint to execute against, engaging in CRM optimisation for effective and efficient solution development, and deploying the solution itself.

The CRM strategy for Harrah's Entertainment, for example, was initiated with a pilot at one property and later was expanded to others. Roche Pharmaceuticals has limited its initial CRM approach to one of its many drugs, with the intention of possibly expanding to others. Finally, 
Sears Canada began its CRM initiative within its catalogue sales channel and gradually extended to others.

In order to facilitate the process of adapting and applying these insights to your own organisation, consider two questions.

- What is the danger to our company if we have not thoughtfully considered an expansion strategy for CRM?

- Where is the greatest opportunity currently to extend the breadth or depth of our CRM initiatives?

\section{Strategy insights}

\section{Organisational breadth}

In review, best practice organisations 'eat the elephant one bite at a time'. Why? Because by so doing, an organisation can balance the speed of implementation with the requirement for flexibility as new knowledge is gained; and build long-term relationships with while demonstrating short-term results to cost-justify subsequent investment.

\section{Summary}

Concerning the first research objective - understanding the principles underlying successful CRM strategies - what did the study reveal? Best practice CRM strategies are characterised by four primary attributes: being holistic and inclusive of multiple stakeholder groups, addressing individual differences along a bonding and value continuum, involving both centralisation and local customisation and developmentally progressing through deployment stages.

\section{Findings: Alignment}

\section{A successful CRM strategy is tightly integrated with numerous functional areas}

CRM may be 'born and nurtured' within the marketing function, but it 'lives' within the remainder of the enterprise. To have a successful CRM implementation - one that delivers business value - it is necessary to incorporate many functional areas. Why? Because it is within these latter areas that strategy is transformed from 'thinking' to 'doing', resulting in superior sales and service.

One measure of CRM organisational maturity is the breadth of involvement among functional areas. Among best practice companies, it is the functional areas of sales, information technology and finance that are most frequently integrated into CRM efforts; to a lesser extent, research and development plus manufacturing/operations and, in some instances, purchasing are also integrated. While the inclusion of sales and information technology is of no surprise, consider the other areas identified: finance, for understanding the economics of CRM (eg customer lifetime value); research and development, for guiding the development of products and services attuned to customer needs; manufacturing/operations, for customising products and services to address customer needs; and purchasing, for developing mutually beneficial relationships with suppliers.

Critical success factors observed among best practice organisations in aligning functional areas to support CRM include: 
— establishing a common vocabulary internally to facilitate relationship marketing discussions

- building a strong partnership with information technology

- educating the functional areas about principles of relationship marketing.

How are these critical success factors manifested within best practice organisations? The Canadian Imperial Bank of Commerce, for example, has multiple functional areas linked to its CRM efforts. With a diversity of personnel including statisticians, process designers, marketers and staff with branch banking experience, significant effort has been expended to build a common and shared vocabulary for terms such as 'knowledge exploitation' (ie using discovered knowledge to re-engineer business processes). A shared vocabulary is a fundamental enabling condition for integrating functional areas to support CRM.

In addition, Harrah's Entertainment, for example, formed a strong partnership with the company's information technology organisation. This partnership is strengthened by the fact that there is one senior vicepresident position to whom both information technology and brand operations report.

Finally, Roche Pharmaceuticals succeeds in part because it trained its sales representatives about the discipline of relationship marketing generally and its XENICare ${ }^{\circledR}$ programme specifically.

In order to facilitate the process of adapting and applying these insights to your own organisation, consider two questions.

- Have we identified the role that each major functional area (eg finance, human resources, manufacturing and operations, marketing, purchasing, research and development, sales and technology) has within our CRM activities today, and how that role must evolve in the future?

- Have we determined the structural organisational changes that will be required to facilitate our CRM success (eg aligning business units with customer portfolios rather than products)?

In review, best practice organisations extend CRM beyond the marketing department to encompass and educate many functional areas across the enterprise.

\section{Best practice organisations rely on an effective change management process to involve all employees in an internal partnership}

This finding has two related components: one addressing change management, and the other focusing on the critical role of employees in achieving CRM success.

\section{Change management}

First, it is noteworthy that best practice companies do not view CRM as a 'marketing programme' to be launched or a software system to be installed, but rather as an organisational change management effort. The goal is not primarily to implement a specific marketing solution or technology, but to reorient the organisation to become customer-centric. 
Consider that the greatest CRM challenge is managing corporate culture change, ${ }^{15}$ and over four-fifths of organisations attribute the failure of their CRM programme to inadequate change management. ${ }^{16}$ Observed critical success factors in driving organisational change ${ }^{17}$ among best practice organisations include:

- establishing a sense of urgency and a guiding coalition

- creating and communicating a vision

- empowering employees to act on the vision.

\section{Employee partnership}

Roche Pharmaceuticals, for example, established urgency, created a vision (ie a 'personal weight-loss coach') and empowered a crossfunctional coalition (including management, marketing, customer service, legal, information technology and sales) when it decided to create and launch the XENICare ${ }^{\circledR}$ CRM programme in 90 days - in order to be active on New Year's Day, when many weight-loss resolutions are made.

The second component of this finding addresses the issue of cultural alignment to support the CRM effort generally and customer service expectations specifically. Critical success factors observed among best practice organisations include the following.

- Identifying and measuring those employee engagement behaviours (eg friendliness and helpfulness) that define service quality for every interaction. In the case of Roche Pharmaceuticals, the patients enrolled in the XENICare ${ }^{\circledR}$ programme rate key dimensions such reliability, empathy and responsiveness.

- Aligning employee recognition and rewards ${ }^{18}$ with CRM goals. Roche Pharmaceuticals, for example, has established a quality programme to recognise the healthcare professionals supporting XENICare ${ }^{\circledR}$, and a quarterly bonus programme to reward them. These recognition and reward programmes are founded upon and linked to successful demonstration of the key employee engagement behaviours.

- Providing employees with the training and tools needed to succeed. It is not sufficient only to understand the employee engagement behaviours desired and to recognise and reward them when they occur, but to enable them to flourish through an investment in education and supporting mechanisms. Roche, for example, provides for its employees two weeks of initial training, side-by-side mentoring, training updates and one-on-one coaching during ongoing monitoring of patient interactions.

In order to facilitate the process of adapting and applying these insights to your own organisation, consider two questions.

- How will we achieve an institutionalisation of relationship marketing within our organisation? Do we view CRM implementation as an organisational transformation effort?

- Does our CRM solution recognise, reward and enable the success of our employees? 
Experiential consistency
In review, best practice organisations succeed because they understand that enterprise-wide CRM necessitates a thoughtful management of organisational change, combined with the partnership and participation of their employees in those transformations.

\section{Best practice organisations provide a consistent customer experience through multiple contact points}

This finding emphasises the importance of a consistent customer experience wherever, whenever and however a customer has contact with your employees or brand. Consistency, by its very nature, is ubiquitous: it needs to occur across geography, sales channels and media - and anywhere else your customer 'touches' the company. Consistency is important in developing successful relationships because, in its absence, trust is reduced - and trust is a foundational condition for authentic and productive relationships. $^{19}$

From this research, there are three noteworthy aspects of consistency.

- Consistency reflects knowledge of the individual by the company by saying to the customer 'we know who you are and what you want'.

- It reinforces the perceived value of the customer to the company by saying to the customer 'we care enough to treat you well all the time'.

- It enhances customer satisfaction by saying to the customer 'we want to match our service to your expectations'.

As a consequence of all of the above, consistency builds commitment between customers and the company over time, thereby enhancing significant business outcomes such as repeat purchase intention, referral propensity and sharing of personal information.

While there is no one mechanism to achieve experiential customer consistency, it is informative to consider some of the ways in which best practices organisations do so.

- Standardising the 'relationship rules' (ie 'if $\mathrm{X}$, then $\mathrm{Y}$ ') of the organisation, in which specific customer behaviours (' $\mathrm{X}$ ') trigger associated communications and service actions (' $Y$ '). As implemented by the Canadian Imperial Bank of Commerce, a customer action - such as product purchase or complaint - causes the relevant number, type and order of standardised messages to be sent.

- Centralising data to provide a unified corporate memory of key relationships, such that all parts of the organisations share equally in knowledge of the customer. The Canadian Imperial Bank of Commerce has also, for example, succeeded in transforming a traditional product-centric database to a customer-centric database by aggregating accounts (products) to individuals, individuals to households, households to marketing portfolios and marketing portfolios to business units.

- Assigning specific service personnel to individual customers, in order to enable a consistent dialogue between the same two people (while 
preparing and rewarding these service personnel to succeed). Roche, for example, excels in providing an outstanding level of customer consistency for participants in its XENICare ${ }^{\circledR}$ CRM programme by assigning specific healthcare professionals (nurses or registered dietitians) in its call centre to specific customers.

In order to facilitate the process of adapting and applying these insights to your own organisation, consider two questions.

- In our organisation, do specific customer behaviours consistently trigger associated communications and service actions?

- How will our front-line employees be enabled to access and use customer-specific data in order to initiate consistent, customised and meaningful conversations?

In review, best practice organisations recognise and seek to achieve experiential customer consistency and, by so doing, build the trust that is so fundamental for productive and authentic relationships.

\section{Importance of brand}

\section{Best practice organisations align the CRM strategy with the brand} The brand encapsulates the 'promise' made by the organisation to its customers, and is enlivened by its employees, channel partners and other stakeholders who are the face of the organisation's brand image.

Achieving a strong brand relationship ${ }^{20}$ with a customer is the pinnacle in a series of stages leading to brand equity, beginning with awareness, proceeding to perceived performance, continuing with brand judgements and feelings, and concluding with active engagement.

The brand dimension of CRM includes both the expectations that the company has of its customers (eg to remain loyal) and the expectations that customers have of the company (eg to receive excellent products/ services at a fair price). If the brand promise and the CRM strategy are misaligned, customer confusion is sure to result together with an erosion of the relationship.

Among the best practice organisations studied, the challenges faced by Roche Pharmaceuticals and its CRM solution for Xenical ${ }^{\circledR}$, a prescription obesity medication, most clearly illustrate the principle of this finding. The prize is a share of the market of the 20 million individuals who would consider using a prescription medication for weight loss. While the branding was warm and friendly, Roche Pharmaceuticals faced serious marketing challenges:

- cost, since the medication is expensive and uncovered by some insurance companies that view it as a 'lifestyle drug'

- compliance by the patient to the prescribed frequency of use

- confusion, since there is a plethora of conflicting (and often inaccurate) information about weight loss.

The solution was XENICare ${ }^{\circledR}$, a brand-specific weight management and patient support programme, promoted as a personal weight-loss coach 


\section{Alignment insights}

that helps the patient change the way they feel and think about food and themselves and teaches the lifestyle skills needed for healthier habits. Consistent with the brand positioning of Xenical ${ }^{\mathbb{R}}$, the programme sought to address key factors that distinguish satisfied from dissatisfied customers, such as knowledge of how the medication works (including mitigation of unpleasant potential side-effects); understanding that the drug acts as a feedback mechanism for eating behaviour; and possessing both short- and long-term weight-loss goals.

In the case of the Canadian Imperial Bank of Commerce, the emphasis on brand was explicitly incorporated into the vision statement for the customer marketing department:

'Customer Marketing is committed to knowing what the customer wants. Smartly. Delivering what customers value. Simply. And speaking with one voice. Clearly. In that way, we will enable the Brand Promise to become a reality for CIBC's customers.'

In order to facilitate the process of adapting and applying these insights to your own organisation, consider two questions.

- Does our CRM solution provide customers with the expected value and service promised by the brand?

- Does our CRM solution prepare and recognise our employees to deliver upon the brand promise?

In review, best practice organisations understand the importance of aligning the CRM solution and the brand promise with each other.

\section{Summary}

Concerning the second research objective - understanding how best practice organisations align their economic and organisational resources and relationships to drive success - what did the study reveal? First, the importance of enlarging CRM beyond the marketing function was observed, to include numerous other functional areas with the objective of encompassing the entire customer interaction continuum. Secondly, successful CRM involves organisational change management and a strong focus upon employees who, in the eyes of most customers, are the company and whose actions account for as much as 70 per cent of a customer's purchase decision. ${ }^{21}$ Thirdly, one saw the emphasis placed upon achieving experiential customer consistency so as to enable trust, a fundamental element of successful relationships. Finally, the study gained insight into the necessity of aligning the CRM efforts together with the brand positioning to ensure that each complements and reinforces the other.

\section{Findings: Measurement}

Best practice organisations build winning relationships through databased insights

This finding addresses the importance of using the stored corporate repository of knowledge about key relationships - otherwise often 


\author{
Data are prerequisite \\ for customised \\ conversations
}

known as a customer database - to achieve customised and meaningful bi-directional conversations which cannot occur in the absence of knowledge of each other. The centrality of data to CRM is not news; what are insightful here, however, are the motivations employed by best practice companies and the critical success factors that enable them to build better relationships through data-based insights.

First, best practice companies deeply understand that unlike existential philosophical issues, all well-formulated marketing questions are empirical and can be answered. How? Through a commitment to a rigorous process of testing to 'hear' the 'voice' of the market-place in order to drive iterative learning and improvement.

While testing is about answering the questions you are already wise enough to ask, the second motivation highlights the importance of discovering unexpected insights through data mining. Best practice organisations, such as the Canadian Imperial Bank of Commerce, view $\mathrm{CRM}$ as an information-driven approach and a 'sustained learning process', all with the objective of identifying marketing interventions that cause beneficial change in customer behaviours. It made the effort to build a 'customer information infrastructure' that not only consisted of data, but also included skills and processes that are collectively designed to deliver upon its CRM strategy. Among large US companies the challenge is massive, with a majority reporting that the quantity of data is doubling or tripling every year. ${ }^{22}$

What are the critical success factors for achieving these outcomes? There are primarily three.

- Capturing actionable data ${ }^{23}$ through careful planning, especially facts that permit the marketer to understand the dimensions of cost (eg acquisition cost, costs per transaction), value (eg revenue by customer, potential versus actual value) and time (eg delivery response time, real-time customer satisfaction) - whether in and of themselves, or as an answer to a marketing hypothesis.

- Transforming customer data to insights by the statistical and algorithmic talents, tools and technology of knowledge discovery.

- Putting insights into action by re-engineering the business process in the light of new customer knowledge, so as ultimately to impact on the customer experience with the brand.

In order to facilitate the process of adapting and applying these insights to your own organisation, consider two questions.

- Does our CRM solution permit the rapid testing of hypotheses?

- Does our organisation use discovered knowledge from the analysis of data to re-engineer business processes with the objective of building better relationships?

In review, best practice organisations emphasise active testing and passive knowledge discovery to leverage data assets, all with the overall 


\section{Measurement plan}

\section{Data quality}

\section{Accountability methods}

aim of enabling meaningful customer dialogue and improving processes so as to enhance the customer experience with the brand.

\section{Best practice organisations achieve CRM accountability}

Less than 1 per cent of all marketers are very satisfied with their ability to measure return on investment, ${ }^{24}$ and the absence of a well-defined business case is a top reason for CRM failure. ${ }^{25}$ The achievement of marketing accountability among best practice organisations, however, is a core characteristic. How is this accomplished?

The first critical success factor is possessing a written and formal measurement plan, reviewed and approved by management, that clearly articulates how success is defined and how it will be computed. A good measurement plan encompasses the use of multiple key performance indicators to provide a holistic view, including not only obvious financial metrics (eg revenue), but also those addressing brand (eg awareness), employees (eg retention), customers (eg cost per new customer) and operational considerations (eg service time). From the financial perspective, the measurement plan specifies the data required for establishing and monitoring the business case, including marketing inputs (costs) and business outputs (revenue) to permit the calculation of closedloop return on investment.

A second factor is rigorously controlling data quality to ensure consistency and completeness of the information gathered. Best practice companies actively emphasise the importance of data quality, including the use of employee recognition and rewards in support of that objective. The issue of data quality is significant, with degradation decay rates estimated at 2.5-3.5 per cent - compounded monthly. ${ }^{26}$

With a measurement plan in place together with quality data, demonstrating marketing accountability occurs through these three main approaches:

- computing individual customer profitability increases, and summing these to achieve an overall marketing impact estimate

- quantifying the return from each individual marketing initiative (eg campaign) using test and control experimental designs, the totality of which serves to justify the CRM strategy within an organisation

- linking employee commitment, customer loyalty and profit ${ }^{27}$ to achieve an overall perspective of marketing investments that impact on multiple audiences.

For example, consider the practices of the Canadian Imperial Bank of Commerce. This organisation embeds data quality into business processes and salesforce operations, and reinforces the importance of data quality through incentive compensation; computes individual customer profitability and loss statements, listing income less fee and service expenses to arrive at individual net customer contributions; and evaluates its own 'Action-Profit Linkage Model' that demonstrates a 5 per cent increase in employee commitment leading to a 2 per cent increase in customer loyalty, resulting in a annual profitability increase of C $\$ 72 \mathrm{~m}^{28}$ 
In a similar vein, Sears Canada demonstrated that a five-point increase in employee satisfaction yields a 1.7 per cent improvement in customer loyalty that drives a 3.4 per cent increase in earnings. ${ }^{29}$

In order to facilitate the process of adapting and applying these insights to your own organisation, consider these questions.

- Do we have a formal and written measurement plan for our CRM strategy? What are the criteria against which success will be judged? Are we capturing the required data to evaluate success?

- How will the quality of our data be rigorously controlled? Have we considered the use of employee training, recognition and rewards?

\section{Measurement insights}

\section{Ecosystem of relationships}

In review, this finding emphasises the important role of a measurement plan and the criticality of quality data, and documents three mechanisms by which accountability is achieved. Consider that the alternative to measurement is intuition, and our instinct is as oft wrong as right. It is only the omniscient that need not measure.

\section{Summary}

Concerning the third research objective - understanding the collection and utilisation of quantitative data to drive and demonstrate marketing accountability - the study revealed that best practice organisations are committed to testing, capture actionable data through careful planning, transform those data into knowledge through rigorous analysis and apply the insights to guide customised conversations and enhance business processes. Marketing accountability is specifically achieved through the possession of a measurement plan, emphasising data quality and computing business value based upon changes in individual customer profitability, quantifying the return from each individual marketing initiative and/or linking investments across multiple audiences (eg employees, customers) to profitability.

Mark Twain once observed, 'Most people use statistics the way a drunkard uses a lamppost - for support rather than illumination.' In contrast to most organisations, best practice organisations use statistics both to support the delivery of value and to illuminate strengths and opportunities for continued success.

\section{Conclusions}

How do best practice organisations achieve the promise of CRM? In examining the set of best practice findings, a half-dozen significant themes emerge.

First, best practice companies understand that customer relationship management per se is inadequate. Building and nurturing sustainable, authentic and productive relationships necessitates identifying the entire ecosystem of interacting associations and, for each pair of constituencies, discerning and balancing the 'give' and the 'get' to achieve reciprocity and relationship equilibrium. ${ }^{30}$ If, in contrast, a company's efforts are solely focused on customer communications, then arguably they are engaging in promotional marketing but not CRM. The primary objective 


\section{Passion and dedication}

Simplicity

\section{Long-term vision, short-term concentration}

\section{Technology}

\section{Outsourcing}

of the former is achieving a sale; of the latter, investing in resilient relationships that yield multiple sales over long periods.

Secondly, best practice organisations are passionate about CRM, are confident that they can excel in creating customer intimacy and know that relationships drive their economic engine. In short, CRM is the "hedgehog concept', ${ }^{31}$ the "northbound train' 32 and the 'very essence of the business itself'. In contrast to a focus on product leadership or operational excellence, these best practice organisations have chosen customer intimacy as the discipline through which market leadership will be achieved. $^{33}$

Thirdly, best practice organisations succeed due to a dedication to simplicity. These companies do not concentrate upon building the most elaborate multi-step, real-time, event-triggered, segmentation-specific, Internet-enabled communication streams; rather, they execute exceedingly well and consistently a selected set of basics. As the noted business author Tom Peters once observed, 'We wildly underestimate the power of the tiniest personal touch. ${ }^{34}$

Fourthly, best practice organisations seek to build better relationships for the long term, but also appreciate the business necessity of showing short-term results along the way. Successfully doing so involves many factors, chief among which are achieving a shared consensus on objectives and the specific business problems to be solved (eg attrition reduction or cross-sell enhancement); prioritising efforts by considering degree of impact and ease of implementation; coordinating with existing initiatives and resources to achieve leverage; testing to minimise downside risk and drive continuous improvement; capturing and transferring knowledge throughout the organisation; employing knowledge discovery to utilise data effectively and uncover unexpected insights; and possessing a dedication to achieving marketing accountability.

Fifthly, best practice organisations understand that technology is an essential enabler and accelerator for building winning relationships, but one that is subordinate to strategy. Technology decisions should be among the last ${ }^{35}$ - not the first - considerations in adopting CRM. Effective relationship initiatives within best practice organisations span the spectrum from 'no-tech' to 'low-tech' to 'high-tech', but always with eye to the end and not to the means. The customer imperative and not the technology implementation is key.

Sixthly, best practice organisations do what they do best and outsource the rest - especially in the early developmental stages. They know what they know, but most importantly they also know what they do not know. Those knowledge-based competencies (eg statistical analysis) and performance-based capabilities (eg call centres) which are internally absent are sought externally. This is in contrast to 40 per cent of all organisations that are attempting CRM strategy or implementation without outside assistance, among which the likelihood of success is reduced by a factor of two or more. ${ }^{36}$

Albert Einstein once defined insanity as 'doing the same thing over and over again and expecting a different result'. To achieve a result different 
from over 80 per cent of European CRM companies $^{37}$ — namely, a business success - it is necessary not only to do things differently, but also to do different things. Among those things are known to be these ten best practices covering the dimensions of strategy, alignment and measurement.

Evaluation

\author{
Prioritisation
}

\section{Adaption and adoption}

\section{Application}

Equipped with insights into practices that distinguish exemplary CRM organisations, what are the next steps in order to achieve the promise of CRM within the reader's own company? A recommended process consists of three major components.

First, evaluate the organisation. Assemble the leadership team of the company representing numerous functional areas and create a consensus rating on each of the ten best practices, judging frequency, quality and scope. Is the best practice done regularly, irregularly or not at all? Is the best practice done well, moderately or poorly? Is the best practice uniformly present or sporadically dispersed across the company?

Secondly, prioritise those best practices that are based upon ease of implementation and business importance. Ask this question: if you are successful in achieving the best practice, what might be the likely impact? Consider the dimensions of revenue, cost of sales, market share, customer service, brand equity and employee culture.

Thirdly, adapt and adopt techniques employed by other successful CRM organisations where appropriate, but also challenge oneself to ask, 'If you could implement any tactic to advance progress toward achieving this best practice, what would be done?' Identify and select the 'must-do' actions from the 'wish list' according to criteria such as measurability, practicality and singularity of purpose. Consider initiatives already in place that are relevant to these 'must-do' actions, the resources available, factors that are helping or hindering forward movement and risk mitigation. Identify and secure assistance from an external partner with expertise that bridges both strategic and technological considerations ${ }^{38}$ to complement and augment the knowledge-based competencies and performance-based capabilities of the organisation. Engage in project planning to define action steps, create measures of success for each, and assign accountability, milestones and budgets. Finally, employ the principles of change management ${ }^{39}$ throughout to increase the scope of impact of the CRM efforts, with the ultimate objective of transforming the organisation into a customer-centric enterprise.

The story is told of Albert Einstein, who was once asked what single event was most helpful in developing the theory of relativity. He answered: 'Figuring out how to think about the problem.' The ten best practices documented in this paper — together with the probing questions provided for each and the recommended methodology to apply the insights — will hopefully assist the reader in thinking anew about the problem of achieving the promise of CRM by directing attention towards facets of the puzzle that otherwise may be neglected. The task of building better relationships with all key constituencies to drive measurable business results is formidable but solvable. These lessons learned from 
the successes of others may serve to inspire us, to guide us and ultimately to reward us.

\section{References}

1. Chatham, B., Weisman, D. E., Orlov, L. M., Nakashima, T. and Howard, E. (2001) CRM: At What Cost?, Forrester Research, Cambridge, MA.

2. Marketing Leadership Council (2001) CRM Success Stories, Marketing Leadership Council, Washington, DC and London.

3. Chatham et al., ref. 1 above.

4. Boslet, M. (2001) 'CRM: The promise, the peril, the eye-popping price', Industry Standard, Vol. 4, No. 30, www.thestandard.com.

5. Colgate, M. R. and Danaher, P. J. (2000) 'Implementing a customer relationship strategy: The asymmetric impact of poor versus excellent execution', Journal of the Academy of Marketing Science, Vol. 28, No. 3, pp. 375-387.

6. Rigby, D., Reichheld, F. F. and Schefter, P. (2002) 'Avoid the four perils of CRM', Harvard Business Review, Vol. 80, No. 2, pp. 101-109.

7. American Productivity and Quality Center (2002) Improving Growth and Profits through Relationship Marketing, APQC, Houston, TX.

8. Gordon, I. (1999) Relationship Marketing: New Strategies, Techniques and Technologies to Win the Customers You Want and Keep Them Forever, John Wiley \& Sons, New York.

9. Marketing Leadership Council (2001) The ties that bind: Evaluating and using loyalty programs as tools for retaining customers, Marketing Leadership Council, Washington, DC and London.

10. O'Malley, M. (2000) Creating Commitment: How to Attract and Retain Talented Employees by Building Relationships that Last, John Wiley \& Sons, New York.

11. Grizzard Performance Group (2002) Customer Retention Marketing: What's Working, www.grizzardpg.com/assets/pdf/surveycrm_2002.pdf.

12. Harrah's Entertainment (2000) Annual Report, Harrah’s Entertainment, Las Vegas, NV.

13. Gordon, ref. 8 above.

14. Robbins, H. A. and Finley, M. (2000) The NEW Why Teams Don't Work: What Goes Wrong and How to Make It Right, Berrett-Koehler, San Francisco.

15. Cap Gemini Ernst \& Young (2001) Paths to Differentiation: 2001 Special Report on the Financial Services Industry, www.ca.cgey.com/news/paths_mediakit/FSR_report.pdf.

16. Rigby et al., ref. 6 above.

17. Kotter, J. P. (1996) Leading Change, Harvard Business School Press, Boston, MA.

18. Farrell, J. (2002) 'Highlighting the 4Rs of marketing', Incentive, Vol. 176, No. 4, p. 101.

19. Morgan, R. M., and Hunt, S. D. (1994) 'The commitment-trust theory of relationship marketing', Journal of Marketing, Vol. 58, No. 3, pp. 20-38.

20. Keller, K. L. (2001) 'Building customer-based brand equity', Marketing Management, Vol. 10, No. 2, pp. 14-19.

21. McKean, J. (2002) Customers Are People ... The Human Touch, John Wiley \& Sons, Chichester.

22. Teradata (2002) The 2002 Teradata Report on Enterprise Decision-Making, www.teradata.com/ mediacenter/EDM_Report_for_Media_Final.pdf.

23. Gordon, ref. 8 above.

24. Marketing Leadership Council (2002) Marketing Investment and Impact Benchmarks, Marketing Leadership Council, Washington, DC and London.

25. Cap Gemini Ernst \& Young, ref. 15 above.

26. Lester, L. Y. (2003) 'Data quality: The foundation for effective CRM', Target Marketing, February, pp. 49-53. 


\section{Achieving the promise of $C R M$}

27. Heskett, J. L., Sasser, W. E. Jr and Schlesinger, L. A. (1997) The Service Profit Chain, Free Press, New York

28. Epstein, M. J. and Westbrook, R. A. (2001) 'Linking actions to profits in strategic decision making', MIT Sloan Management Review, Vol. 42, No. 3, pp. 39-49.

29. Norquist, M. (2002) 'A great place to shop, work and invest: Measuring and managing the service profit chain at Sears Canada', Interactive Marketing, Vol. 3, No. 3, pp. 255-261.

30. Batterley, R. (2002) 'Plot your route to success', Australian Banking and Finance, Vol. 11, No. 13 , p. 11.

31. Collins, J. (2001) Good to Great: Why Some Companies Make the Leap ... and Others Don't, HarperCollins, New York.

32. Albrecht, K. (1994) The Northbound Train: Finding the Purpose Setting the Direction Shaping the Destiny of Your Organisation, AMACOM, New York.

33. Treacy, M. and Wiersema, F. (1997) The Discipline of Market Leaders: Choose Your Customers, Narrow Your Focus, Dominate Your Market, Perseus Publishing, Reading, MA.

34. Peters, T. (1991) 'A tiny human touch goes a long, long way', www.tompeters.com.

35. Geiger, S. (2001) 'Successful CRM is more than a quick technology fix', iMarketing News, Vol. 3, No. 18, pp. 9-12.

36. Doane, M. (2002) The Overwhelming Failure of Go-It-Alone CRM, META Group, Stamford, CT.

37. Middleton Hughes, A. (2002) 'The mirage of CRM', Journal of Database Marketing, Vol. 9, No. 2, pp. 102-104.

38. Nykamp, M. (2002) 'The ins and outs of outsourcing', Direct, Vol. 14, No. 2, p. 57.

39. Kotter, ref. 17 above. 